Интернет-журнал «Отходы и ресурсы» / Russian journal of resources, conservation and recycling http://resources.today 2016, Том 3, №2 / 2016, Vol 3, No 2 http://resources.today/issues/vol3-no2.html

URL статьи: http://resources.today/PDF/07RRO216.pdf

DOI: 10.15862/07RRO216 (http://dx.doi.org/10.15862/07RRO216)

Ссылка для цитирования этой статьи:

Сумзина Л.В., Кочеткова Я.А., Аржанов П.А., Бурцев И.А., Литвиненко А.А. Влияние рекуперативного теплообмена на эффективность цикла холодильного агрегата // Интернет-журнал «Отходы и ресурсы» Том 3 , №2 (2016) http://resources.today/PDF/07RRO216.pdf (доступ свободный). Загл. с экрана. Яз. рус., англ.

For citation:

Sumzina L.V., Kochetkova Ja.A., Arzhanov P.A., Burcev I.A., Litvinenko A.A. [The effect of regenerative heat transfer on cycle efficiency of the refrigeration unit] Russian journal of resources, conservation and recycling, 2016, Vol. 3, no. 2. Available at: http://resources.today/PDF/07RRO216.pdf (In Russ.)

\title{
УДК 621.56
}

Сумзина Лариса Владимировна ФГБОУ ВО «Российский государственный университет туризма и сервиса», Россия, дп. Черкизово Доцент кафедры «Сервисного инжиниринга» Кандидат технических наук E-mail: byttech1@yandex.ru

Кочеткова Яна Александровна ФГБОУ ВО «Российский государственный университет туризма и сервиса», Россия, дп. Черкизово Старший преподаватель кафедры «Сервисного инжиниринга» E-mail: jana.sirtenk@yandex.ru

Аржанов Павел Андреевич ФГБОУ ВО «Российский государственный университет туризма и сервиса», Россия, дп. Черкизово Магистрант E-mail: arzhanov69@mail.ru

Бурцев Игорь Александрович ФГБОУ ВО «Российский государственный университет туризма и сервиса», Россия, дп. Черкизово Магистрант E-mail: burtzev.igor@yandex.ru

Литвиненко Анатолий Александрович ФГБОУ ВО «Российский государственный университет туризма и сервиса», Россия, дп. Черкизово Доцент кафедры «Сервисного инжиниринга» Кандидат технических наук E-mail: anatol.litvinenko@gmail.com

\section{Влияние рекуперативного теплообмена на эффективность цикла холодильного агрегата}

Аннотация. Решение проблемы повышения энергоэффективности бытовой холодильной техники связано с повышением термодинамической эффективности холодильных циклов. Одним из методов повышения термодинамической эффективности является совершенствование схем холодильных агрегатов.

Задачей работы являлось определение степени влияния рекуперативного теплообмена на термодинамическую эффективность холодильных циклов на основе исследования 
эффективности разработанной схемы агрегата с переохлаждением жидкого хладагента перед испарителем.

При разработке и решении задачи исследования влияния рекуперативного теплообмена на термодинамическую эффективность холодильных циклов применялись теоретические и экспериментальные методы исследования. Метод системно-структурного анализа использовался при разработке технического решения схемы холодильного агрегата. Экспериментальные методы исследований использовались в процессе проведения исследований разработанной схемы агрегата с переохлаждением жидкого хладагента перед испарителем.

Проведены испытания по определению температурно-энергетических показателей холодильника с базовой и разработанной авторами схемой холодильного агрегата в непрерывном и цикличном режимах работы.

Анализ результатов экспериментальных исследований показывает, что в модернизированном холодильнике с рекуперативным теплообменником-докипателем в режиме непрерывной работы снижается температурный уровень в холодильной и низкотемпературной камерах.

Проведенное сравнение полученных результатов экспериментов показывает, что в модернизированном холодильнике с рекуперативным теплообменником-докипателем при цикличной работе на 5\% снижается коэффициент рабочего времени и энергопотребление по сравнению с базовой моделью.

Ключевые слова: холодильный цикл; термодинамическая эффективность; холодильный агрегат; холодильный агент; переохлаждение; энергопотребление

\section{Введение}

Бытовые холодильники в настоящее время составляют значительную часть рынка бытовой техники, внося существенный вклад в энергопотребление. Тенденции развития современной бытовой холодильной техники заключаются в увеличении внутреннего объема камер, снижении температур в низкотемпературных и морозильных камерах. Реализация указанной тенденции приводит к росту энергопотребления в быту и требует разработки энергоэффективных моделей холодильников и морозильников.

Решение проблемы повышения энергоэффективности бытовой холодильной техники связано с повышением термодинамической эффективности холодильных циклов. Одним из методов повышения термодинамической эффективности является совершенствование схем холодильных агрегатов. Данной тематике посвящен ряд работ отечественных и зарубежных исследователей: Колосова Н.В., Лапшина К.Н. [1], Братута Э.Г., Харлампиди Д.Х., Шерстюк В.Г. [2], Юша В.Л., Сухов Е.В. [3], Лемешко М.А., Урунов С.Р., Головина Е.И. [4], Калнинь И.М., Фадеков К.Н. [5], Максимов А.В., Сумзина Л.В., Литвиненко А.А. [6, 7, 8], Lemmon E.W., Huber M.L. [9], Awad M.M., Dalkilic A.S., Wongwises S. [10], Satish G. Kandlikar, Srinivas Garimella [11].

Задачей работы являлось определение степени влияния рекуперативного теплообмена на термодинамическую эффективность холодильных циклов на основе исследования эффективности разработанной схемы агрегата с переохлаждением жидкого хладагента перед испарителем.

\section{Методы исследования}

При разработке и решении задачи исследования влияния рекуперативного теплообмена на термодинамическую эффективность холодильных циклов применялись теоретические и экспериментальные методы исследования. Метод системно-структурного анализа 
использовался при разработке технического решения схемы холодильного агрегата. Экспериментальные методы исследований использовались в процессе проведения исследований разработанной схемы агрегата с переохлаждением жидкого хладагента перед испарителем.

\section{Результаты}

Произведены экспериментальные исследования холодильника с новой, разработанной схемой холодильного агрегата. Новизна разработанной схемы защищена патентом на полезную модель № 155687 [8].

Для проведения исследований бытового двухкамерного холодильника с базовой и модернизированной схемой холодильного агрегата использовалась климатическая термостатированная камера для испытания холодильной техники. Управление работой нагревательных и охлаждающих приборов осуществлялось 8-канальным универсальным измерителем - регулятором «Овен» ТРМ 138, а контроль температурных параметров производился при помощи термопар TXK (L), подключенных к этому прибору.

Условия проведения испытания холодильника с базовой и модернизированной схемой холодильного агрегата были следующими:

- $\quad$ температура окружающего воздуха: $\mathrm{t}_{\mathrm{oc}}=16^{\circ} \mathrm{C}, \mathrm{t}_{\mathrm{oc}}=25^{\circ} \mathrm{C}, \mathrm{t}_{\mathrm{oc}}=32^{\circ} \mathrm{C}$;

- $\quad$ рекомендуемая температура в холодильной камере при цикличной работе холодильника: $\mathrm{t}_{\mathrm{x \kappa}}=+5^{\circ} \mathrm{C}$;

- $\quad$ рекомендуемая температура испытательных пакетов в низкотемпературной камере при цикличной работе холодильника: $\mathrm{t}_{\text {нтк }}=-18^{\circ} \mathrm{C}$ или ниже;

- $\quad$ измерения проводились ровно 24 часа после выхода холодильника на установившийся режим работы в закрытом состоянии.

Разработанная схема холодильного агрегата [8] представлена на рис. 1.

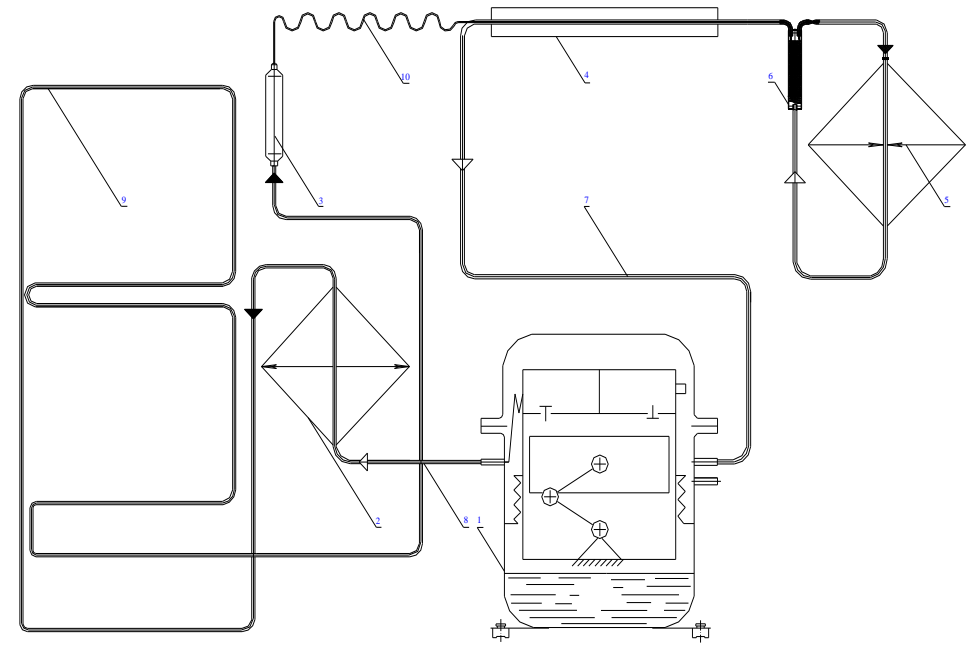

Рисунок 1. Схема холодильного агрегата [8]: 1 - компрессор; 2- конденсатор;

3 - фильтр-осушитель; 4 - рекуперативный теплообменник; 5 -испаритель;

6 - теплообменник-докипатель; 7 - всасывающий трубопровод; 8 - нагнетательный

трубопровод; 9 - петля обогрева дверного проема; 10 - капиллярная трубка (разработано авторами)

На рис. 2 и 3 приведены результаты испытаний базовой и разработанной моделей холодильника. 
Интернет-журнал «Отходы и ресурсы»

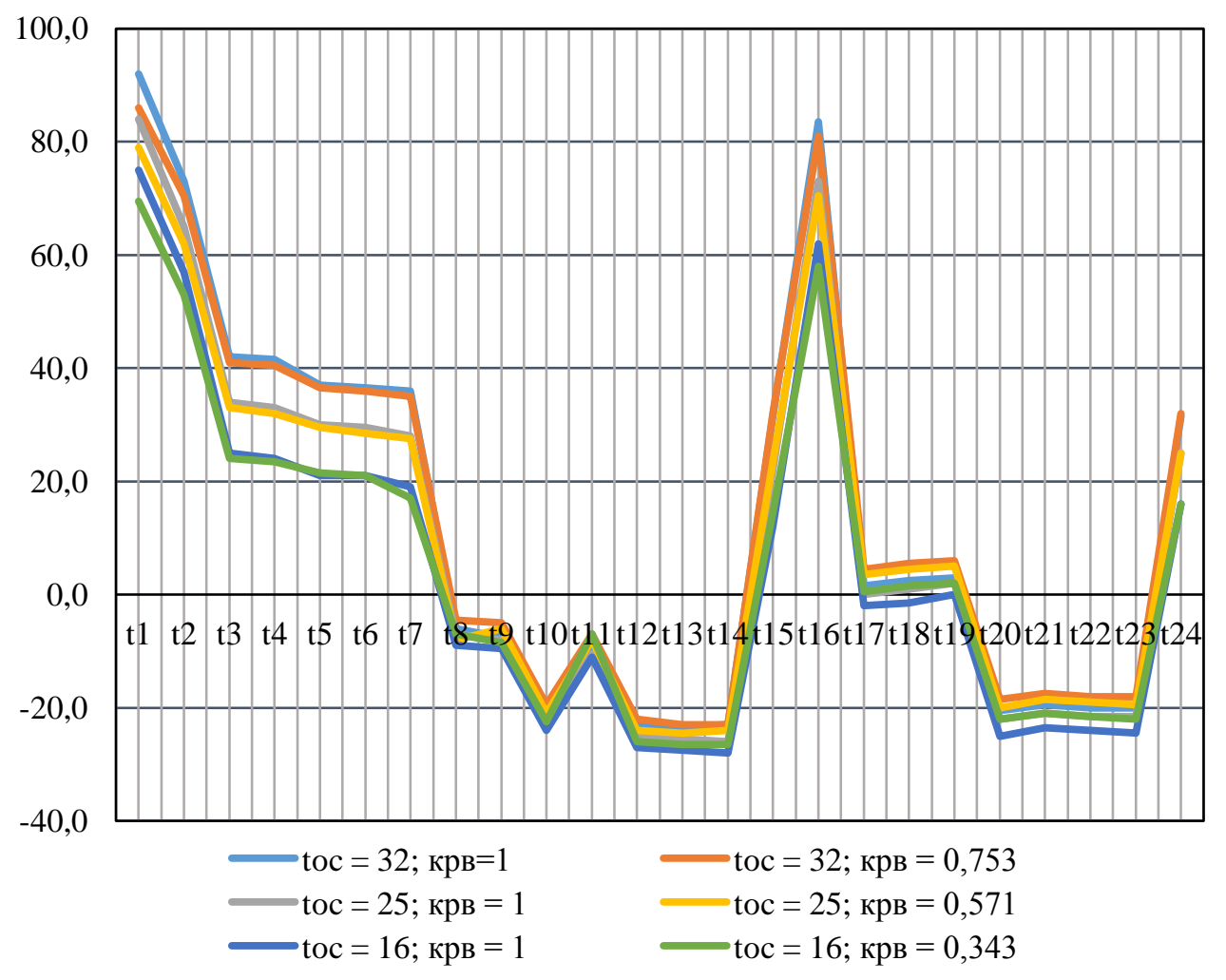

Рисунок 2. Температурное поле базовой модели (рисунок авторов)

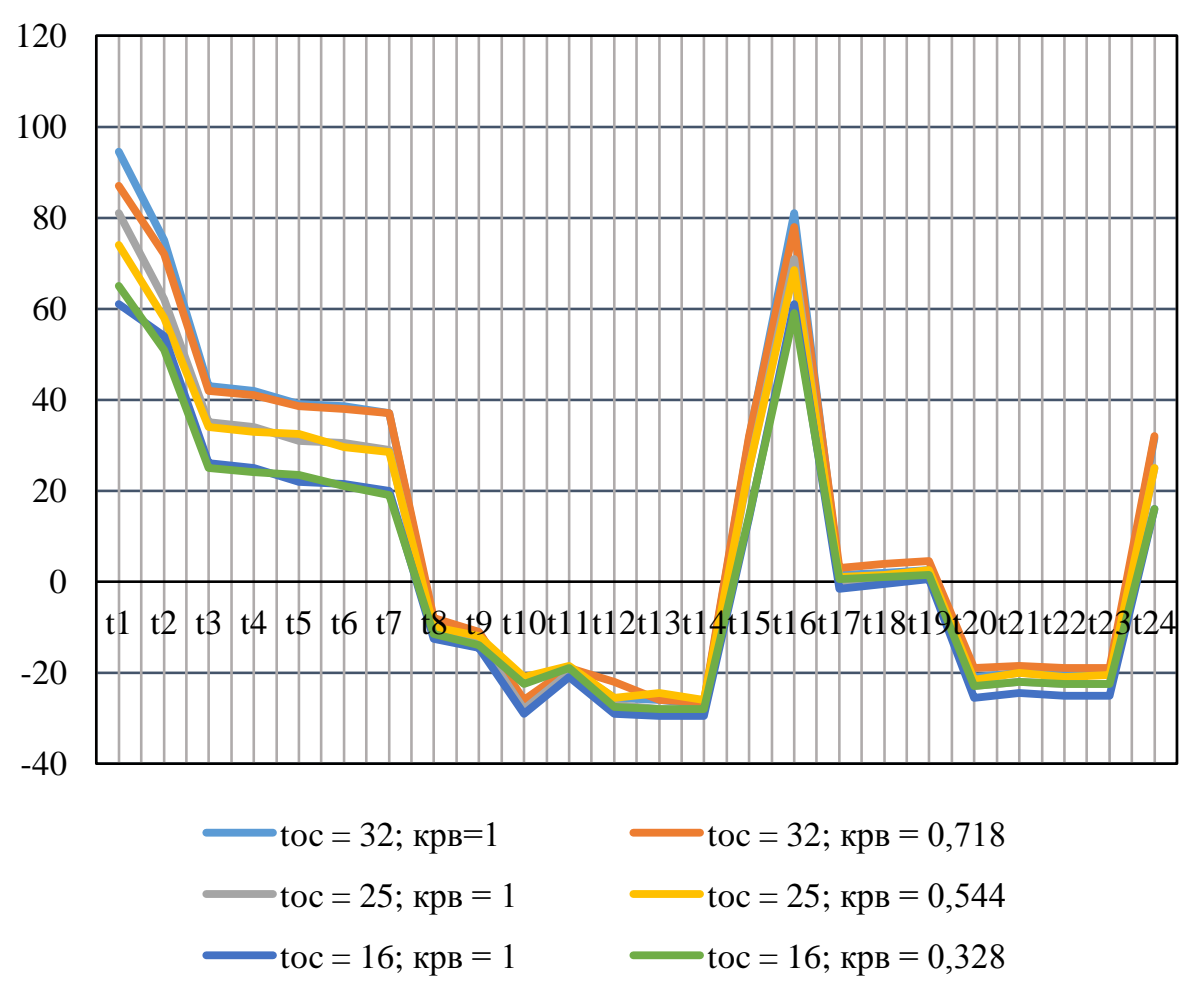

Рисунок 3. Температурное поле с разработанной схемой холодильного агрегата (рисунок авторов)

Сравнительный анализ полученных результатов (рис. 2 и рис. 3) показывает, что в холодильнике $\mathrm{c}$ разработанной схемой холодильного агрегата с теплообменником- 
докипателем [8] более низкий температурный уровень в холодильной и низкотемпературной камерах при тех же значениях температуры окружающей среды.

На рисунках 4 и 5 приведены основные показатели работы холодильника: изменение коэффициента рабочего времени при цикличной работе и расхода электроэнергии для базового и модернизированного холодильника.

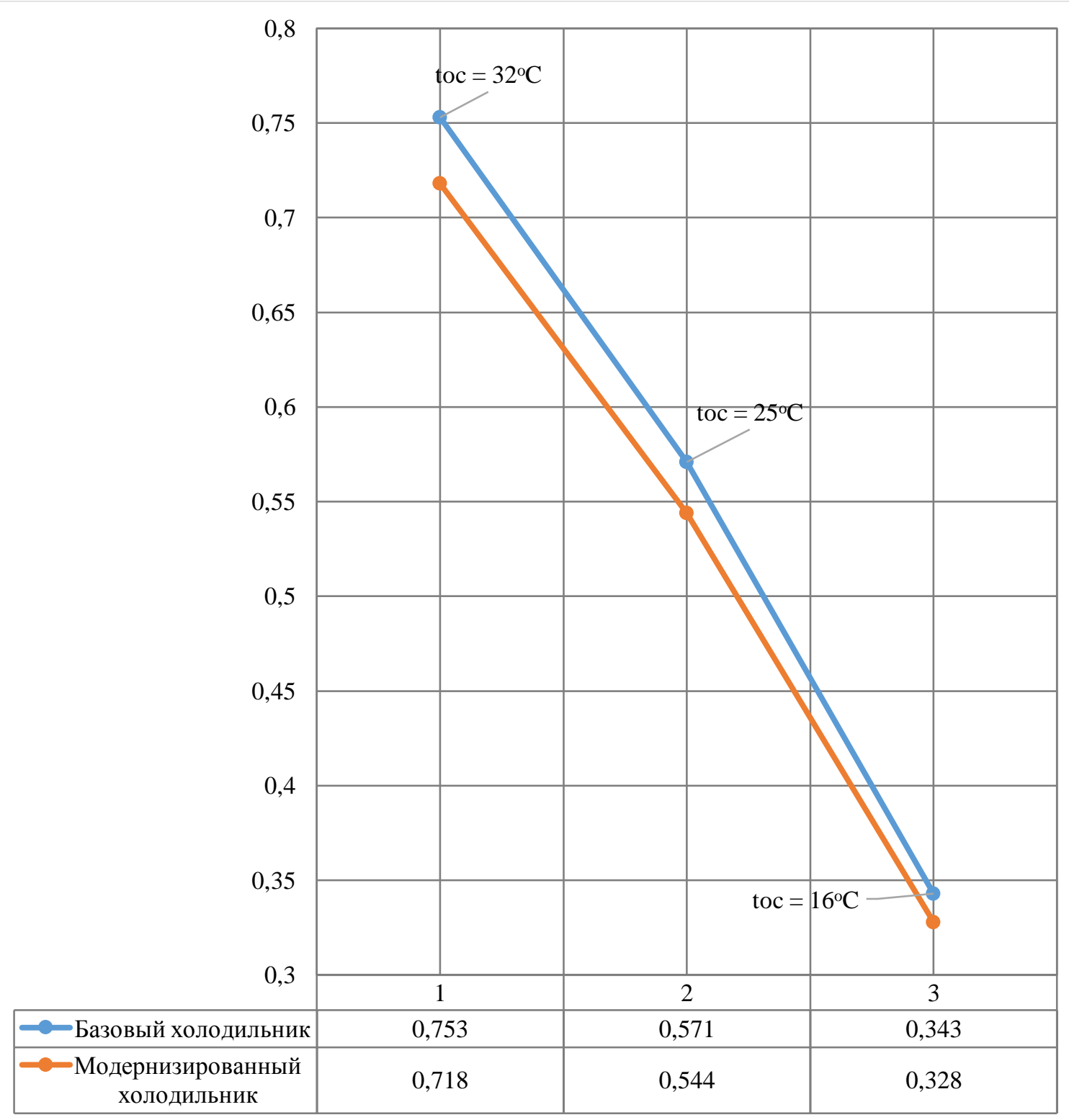

Рисунок 4. Изменение коэффициента рабочего времени при цикличной работе базового и разработанного холодильника (разработано авторами)

Анализ данных, приведенных на рис. 4, показывает, что включение в схему холодильного агрегата рекуперативного теплообменника-докипателя приводит к снижению коэффициента рабочего времени в среднем, на 4,6\% по сравнению с базовой моделью холодильника. 


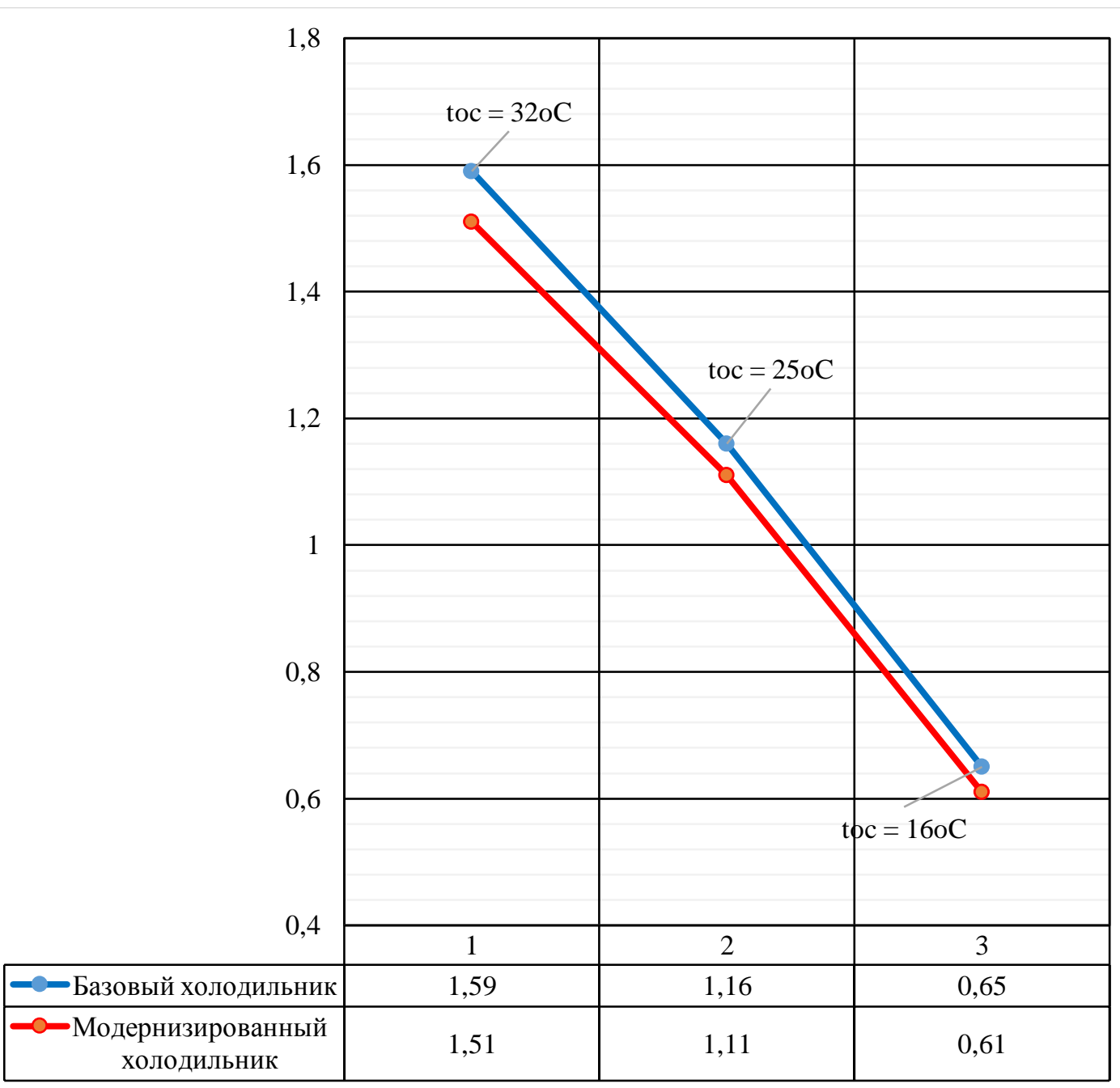

Рисунок 5. Изменение расхода электроэнергии при цฺиклиной работе базового и разработанного холодильника (разработано авторами)

Анализ результатов, приведенных на рис. 5, показывает, что включение в схему холодильного агрегата рекуперативного теплообменника-докипателя приводит к снижению энергопотребления холодильника в среднем, на 5\% по сравнению с базовой моделью.

\section{Заключение}

Проведены испытания по определению температурно-энергетических показателей холодильника с базовой и разработанной авторами схемой холодильного агрегата в непрерывном и цикличном режимах работы.

Анализ результатов экспериментальных исследований показывает, что в модернизированном холодильнике с рекуперативным теплообменником-докипателем в режиме непрерывной работы снижается температурный уровень в холодильной и низкотемпературной камерах.

Проведенное сравнение полученных результатов экспериментов показывает, что в модернизированном холодильнике с рекуперативным теплообменником-докипателем при цикличной работе на 5\% снижается коэффициент рабочего времени и энергопотребление по сравнению с базовой моделью. 


\section{ЛИТЕРАТУРА}

1. Аналитическое решение критериального уравнения теплообмена в контактноповерхностных теплообменных аппаратах. Колосова Н.В., Лапшина К.Н. Научный журнал. Инженерные системы и сооружения. 2014. Т. 2. №4 (17). С. 26-32.

2. Влияние гидравлических сопротивлений на энергетическую эффективность цикла холодильной машины в зависимости от сложности ее технологической схемы. Братута Э.Г., Харлампиди Д.Х., Шерстюк В.Г. Труды Одесского политехнического университета. 2007. №1. С. 98-105.

3. Инженерный анализ компактных теплообменных устройств типа «труба в трубе» со спирально-змеевиковой проточной частью для компрессорных и холодильных агрегатов. Юша В.Л., Сухов Е.В., Машков Ю.К., Сорокин В.Н., Гладенко А.А. Компрессорная техника и пневматика. 2012. №2. С. 33.

4. Использование испарительного охлаждения для увеличения энергетической эффективности бытового холодильника. Оценка эффективности термодинамических циклов парокомпрессионных холодильных машин и тепловых насосов. Калнинь И.М., Фадеков К.Н. Холодильная техника. 2006. №3. C. 16-25.

5. Оценка эффективности термодинамических циклов парокомпрессионных холодильных машин и тепловых насосов. Калнинь И.М., Фадеков К.Н. Холодильная техника. 2006. №3. С. 16-25.

6. Сумзина Л.В., Максимов А.В., Литвиненко А.А. Анализ распределения энергетических ресурсов предприятия сервиса. Вісник Хмельницького національного університету, №3, 2013.

7. Sumzina L.V., Maximov A.V., Litvinenko A.A. Development of the Performance Indicators of the Energy-Efficiency Measures for the Hotels / World Applied Sciences Journal 30 (Management, Economics, Technology \& Tourism): 66-68, 2014.

8. Пат. на полезную модель № 155867. Российская Федерация, МПК F 25 D 11/00/. Холодильный агрегат с теплообменником-докипателем [Текст] / Максимов А.В., Сумзина Л.В., Кочеткова Я.А.; заявитель и патентообладатель ФГБОУ ВО «РГУТИС». - № 2015120456/13, заявл. 29.05.2015; опубл. 20.10.2015, Бюл. №29. $-2 \mathrm{c}$.

9. Lemmon E.W., Huber M.L., McLinden M.O. NIST Reference Fluid Thermodynamic and Transport Properties -REFPROP. Version 8.0. - Gaithersburg, Maryland, 2007. $51 \mathrm{p}$.

10. M.M. Awad, A.S. Dalkilic, S. Wongwises. A Critical Review on Condensation Heat Transfer in Microchannels and Minichannels. Journal of Nanotechnology in Engineering and Medicine, Febrary 2014, Vol. 5.

11. Satish G. Kandlikar, Srinivas Garimella, Dongqing Li, Stephane Colin, Michael R. King. Heat Transfer and Fluid Flow in Minichannels and Microchannels. 2006 Elsevier Ltd. ISBN: 0-0804-4527-6. 
Sumzina Larisa Vladimirovna

Russian state university of tourism and service, Russia, Cherkizovo

E-mail: byttech1@yandex.ru

Kochetkova Jana Aleksandrovna

Russian state university of tourism and service, Russia, Cherkizovo E-mail: jana.sirtenk@yandex.ru

Arzhanov Pavel Andreevich

Russian state university of tourism and service, Russia, Cherkizovo

E-mail: arzhanov69@mail.ru

Burcev Igor' Aleksandrovich

Russian state university of tourism and service, Russia, Cherkizovo

E-mail: burtzev.igor@yandex.ru

Litvinenko Anatolij Aleksandrovich

Russian state university of tourism and service, Russia, Cherkizovo E-mail: anatol.litvinenko@gmail.com

\title{
The effect of regenerative heat transfer on cycle efficiency of the refrigeration unit
}

\begin{abstract}
The solution to the problem of energy efficiency of household refrigeration equipment is associated with an increase in the thermodynamic efficiency of refrigeration cycles. One method of improving the thermodynamic efficiency is improved circuits of refrigeration units.
\end{abstract}

The goal of the study was to determine the influence of regenerative heat transfer on the thermodynamic efficiency of refrigeration cycles on the basis of studies of the effectiveness of the developed scheme of the unit by subcooling the liquid refrigerant before the evaporator.

In the formulation and solution of the problem of research of influence of regenerative heat transfer on the thermodynamic efficiency of refrigeration cycles used theoretical and experimental methods of research. The method of systemic structural analysis used in the development of technical solution schemes of the refrigeration unit. The experimental methods used in the process of conducting research designed scheme of Assembly with subcooling of liquid refrigerant upstream of the evaporator.

Conducted tests to determine the temperature and energy performance of the refrigerator with a base and the authors developed the scheme of the refrigeration unit in continuous and cyclic modes.

Analysis of experimental results shows that, in a modified fridge with recuperative heat exchanger-datepalm in the continuous mode reduces the temperature level in the refrigerating and low-temperature chambers.

A comparison of the experimental results shows that, in a modified fridge with recuperative heat exchanger-datepalm during cyclical operation by $5 \%$ decreases the coefficient of working time and power consumption compared to the base model.

Keywords: refrigeration cycle thermodynamic efficiency; cooling unit; refrigerant; hypothermia; consumption 


\section{REFERENCES}

1. Analiticheskoe reshenie kriterial'nogo uravnenija teploobmena $\mathrm{v}$ kontaktnopoverhnostnyh teploobmennyh apparatah. Kolosova N.V., Lapshina K.N. Nauchnyj zhurnal. Inzhenernye sistemy i sooruzhenija. 2014. T. 2. №4 (17). S. 26-32.

2. Vlijanie gidravlicheskih soprotivlenij na jenergeticheskuju jeffektivnost' cikla holodil'noj mashiny v zavisimosti ot slozhnosti ee tehnologicheskoj shemy. Bratuta Je.G., Harlampidi D.H., Sherstjuk V.G. Trudy Odesskogo politehnicheskogo universiteta. 2007. №1. S. 98-105.

3. Inzhenernyj analiz kompaktnyh teploobmennyh ustrojstv tipa «truba v trube» so spiral'no-zmeevikovoj protochnoj chast'ju dlja kompressornyh i holodil'nyh agregatov. Jusha V.L., Suhov E.V., Mashkov Ju.K., Sorokin V.N., Gladenko A.A. Kompressornaja tehnika i pnevmatika. 2012. №2. S. 33.

4. Ispol'zovanie isparitel'nogo ohlazhdenija dlja uvelichenija jenergeticheskoj jeffektivnosti bytovogo holodil'nika. Ocenka jeffektivnosti termodinamicheskih ciklov parokompressionnyh holodil'nyh mashin i teplovyh nasosov. Kalnin' I.M., Fadekov K.N. Holodil'naja tehnika. 2006. №3. S. 16-25.

5. Ocenka jeffektivnosti termodinamicheskih ciklov parokompressionnyh holodil'nyh mashin i teplovyh nasosov. Kalnin' I.M., Fadekov K.N. Holodil'naja tehnika. 2006. №3. S. 16-25.

6. Sumzina L.V., Maksimov A.V., Litvinenko A.A. Analiz raspredelenija jenergeticheskih resursov predprijatija servisa. Visnik Hmel'nic'kogo nacional'nogo universitetu, №3, 2013.

7. Sumzina L.V., Maximov A.V., Litvinenko A.A. Development of the Performance Indicators of the Energy-Efficiency Measures for the Hotels / World Applied Sciences Journal 30 (Management, Economics, Technology \& Tourism): 66-68, 2014.

8. Pat. na poleznuju model' № 155867. Rossijskaja Federacija, MPK F 25 D 11/00/. Holodil'nyj agregat s teploobmennikom-dokipatelem [Tekst] / Maksimov A.V., Sumzina L.V., Kochetkova Ja.A.; zajavitel' i patentoobladatel' FGBOU VO «RGUTIS». - № 2015120456/13, zajavl. 29.05.2015; opubl. 20.10.2015, Bjul. №29. $2 \mathrm{~s}$.

9. Lemmon E.W., Huber M.L., McLinden M.O. NIST Reference Fluid Thermodynamic and Transport Properties -REFPROP. Version 8.0. - Gaithersburg, Maryland, 2007. $51 \mathrm{p}$.

10. M.M. Awad, A.S. Dalkilic, S. Wongwises. A Critical Review on Condensation Heat Transfer in Microchannels and Minichannels. Journal of Nanotechnology in Engineering and Medicine, Febrary 2014, Vol. 5.

11. Satish G. Kandlikar, Srinivas Garimella, Dongqing Li, Stephane Colin, Michael R. King. Heat Transfer and Fluid Flow in Minichannels and Microchannels. 2006 Elsevier Ltd. ISBN: 0-0804-4527-6. 